\title{
Research on B2C E-Commerce Business Model Based on System Dynamics
}

\author{
Jian Chen'1, Zhicheng Guo², Yin Tang ${ }^{2 *}$ \\ ${ }^{1}$ School of Management, Xinhua College of Sun Yat-sen University, Guangzhou, China \\ ${ }^{2}$ Management School, Jinan University, Guangzhou, China \\ Email: ${ }^{\star T a n g y i n @ t o m . c o m ~}$
}

How to cite this paper: Chen, J., Guo, Z.C. and Tang, Y. (2019) Research on B2C E-Commerce Business Model Based on System Dynamics. American Journal of Industrial and Business Management, 9, 854-874.

https://doi.org/10.4236/ajibm.2019.94058

Received: March 12, 2019

Accepted: April 12, 2019

Published: April 15, 2019

Copyright $\odot 2019$ by author(s) and Scientific Research Publishing Inc. This work is licensed under the Creative Commons Attribution International License (CC BY 4.0).

http://creativecommons.org/licenses/by/4.0/

\begin{abstract}
Based on the perspective of value creation, this paper focuses on the business model of $\mathrm{B} 2 \mathrm{C}$ e-commerce, and tries to figure out how to establish a business model, in order to bring sustainable value creation for businesses and effectively promote the healthy and sustainable development of the businesses of B2C e-commerce. Based on the review of the related researches of business models and e-business models, this paper analyzes components of business model of $\mathrm{B} 2 \mathrm{C}$ e-commerce and explores their relationship. The paper then divides e-business model of $\mathrm{B} 2 \mathrm{C}$ e-commerce into three sub-models: value proposition, value creation and delivery, value capture, based on which we build the system dynamics model of business model of B2C e-commerce. Lastly, we analyze this model using System Dynamics with qualitative and quantitative research, exploring the value creation process and the dynamic process of this model.
\end{abstract}

\section{Keywords}

B2C E-Commerce, Business Model, Value Creation, System Dynamics

\section{Introduction}

B2C e-commerce (Business-to-Consumer) refers to the fact that enterprises sell products and services to individual consumers, which has become the mainstream shopping method in China, and the competition is becoming increasingly fierce. How B2C e-commerce companies stand out in fierce market competition, in addition to their own strengths, the Business Model is also the key to maintaining their core competitiveness, and it is also the basis for providing customers with greater value and surpassing their competitors [1] [2]. With the rapid development of e-commerce, the concept of business model is widely con- 
cerned [3]. However, the vague definition of the e-commerce business model concept and the superficial interpretation make it difficult for enterprises to accurately grasp and apply business models to guide enterprise practice [4].

In order to answer the question "What is the business model?" and explain how business models can create value for the business [5], scholars have used different expressions such as conceptualization, elementization and modeling to describe and analyze business models [6]. Researches on modeling have achieved relatively rich results in recent years, such as EBMO (E-Business Model Ontology), BMC (Business Model Canvas), e3-value model, four-element model, six-element model [7] [8] [9] [10] [11], etc.

Another fundamental problem in the study is still not well understood: how the business model evolves and develops as the company continues to create value [12]. Most of the existing business model expression models still belong to static analysis [13] [14] [15]. That is, the current business model research does not focus on the research of its development process and dynamic evolution, leading companies and managers to fail to understand the elements behind the business model and their interrelationships, and thus fail to understand how to use business models to guide the success of the business [10]. Changes such as economics, competition, etc. will cause companies to change the components of the business model, thus making the business model change in the dynamics [16]. Due to the complex relationship between the constituent elements and elements in the business model, researchers and managers are understanding the dynamic process of the $\mathrm{B} 2 \mathrm{C}$ e-commerce business model, paying particular attention to the important issues such as the relationship between the elements and the dynamics of the entire system [13]. Therefore, in order to accurately apply and grasp business models to guide business practice, scholars and managers must accurately and comprehensively understand the dynamic process of value creation and its elements of business models.

In order to solve the above problems, this article takes the B2C e-commerce business model as the research object, draws on Osterwalder's EBMO e-commerce business model and business model canvas, and constructs the business model expression model and its constituent elements from the perspective of value creation, including three subsystems: value proposition, value creation and transmission, and value acquisition. The system dynamics simulation modeling method is used to qualitatively and quantitatively analyze the value creation process and dynamic evolution process of the model.

Next, the article firstly reviews the research results of business models and e-commerce business models at home and abroad, and analyzes the research results of e-commerce business model expression model and business model dynamic evolution from the perspective of value creation. On this basis, the subsystems of the B2C e-commerce business model are constructed respectively. And then, based on the causal loop graph and the stock flow graph of the model, the system dynamics theory method is used to qualitatively and quantitatively analyze the model, and the key variables of the model are obtained, and the si- 
mulation results of the model are summarized. Finally, based on the simulation results, strategies and recommendations are proposed.

\section{Research Status at Domestic and Abroad}

Osterwalder and Pigneur proposed an EBMO model based on the four dimensions of product innovation, customer relationship, internal management and finance, and identified nine key elements of the model. And the relationship between the components was described from a static perspective [7]. Furthermore, they proposed the Business Model Canvas (BMC), which finally identified nine building blocks. They believed that the business model can be well described and defined through these nine basic building blocks and the logic of generating income (value creation) [14]. Research on the dynamic evolution of business models [1] [10] has only received attention in recent years. According to the issue of Long Range Planning, a special issue on business models in 2010, summed up the dynamics of business models [17]. There are three main theoretical orientations: interactive evolution of business model elements, trial-and-error learning orientation, adaptation or change process model. The current study of the changes of business model pays more attention to its constituent elements, but ignores the study of the interrelationship between constituent elements [11] [18]. Most studies still focus on the business model concept to discuss its changes, and less on how the business model itself changes [19].

Quantification of theoretical research is one of the future trends of business models [4]. Johnson's four-element model studies the elements of business models and the interrelationships between them. From a strategic perspective, qualitative methods are used to illustrate the complex dynamics and evolution of business models. The business model " $3-4-8$ " has been innovative, and has made a profound qualitative analysis of the composition of the business model and the interrelationship between the internal elements and the evolution process of the expression model [15]. Achtenhagen and Melin et al. examine the important supporting role of the three key dynamic capabilities of business models in enterprise value creation in the context of dynamic capabilities and strategic practice. And it also identifies key elements and key issues that need to be addressed for managers in the process of developing and changing business models that continue to create value for the business [1]. Demil and Lecocq used the RCOV framework to analyze the evolution of the business model and the dynamic behavior of the interactive evolution of business model components. The ten-year development of the British football club Arsenal was used as a case to demonstrate the validity of the model [18].

In order to further study the dynamic evolution of business models from qualitative and quantitative research, network modeling and system dynamics methods are applied in the study of the components of business models, the status of elements and the relationship between elements [15]. Dong Shuang established a system dynamics model of telecom business model based on value net- 
work. The interaction between each subsystem was studied by quantitative and qualitative, static and dynamic research methods [20]. Grasl proposes multiple methods to analyze the structure, behavior and dynamics of business models based on system dynamics, and analyzes the dynamic process of value creation of business models [21]. Hajiheydari and Zarei believe that system dynamics is operational, quantifiable and flexible in the simulation study of business models [22]. Therefore, this method is used to construct a dynamic business model dynamics model based on EBMO model. The results show that the business model is changed. Decision making can cause complex dynamic behaviors of the components of a business model, while causing non-linear and complex changes in other elements. Li Yuying researched the Internet of Things business model based on value network and used system dynamics to dynamically analyze the model [23]. Dai Ming and Chen Luojun analyzed the relationship between the various elements in the CSO business model, and used the system dynamics to simulate the model [24]. On the basis of case studies, You Jianping constructed a system dynamics model of the impact of real estate business models on firm growth, and identified key influencing factors in different periods of business model growth [25].

\section{B2C E-Commerce Business Model Building}

Based on the value creation perspective, this paper builds a value proposition subsystem, a value creation and transfer subsystem, and a value acquisition subsystem based on the value creation perspective (Figures 1-4). From value proposition to value creation and transmission to value acquisition, it expresses the complete logic of business operation and helps to understand the basic connotation of the business model.

The three subsystems are interrelated and interacting subsystems, the building blocks of which are further illustrated in Table 1.

\section{System Dynamics Analysis of B2C E-Commerce Business Model}

Based on the value creation perspective, the $\mathrm{B} 2 \mathrm{C}$ e-commerce business model is divided into the value proposition subsystem, the value creation and delivery subsystem, and the value acquisition subsystem. These three subsystems are not a linear relationship, but a "value triangle" with mutual relationship. This paper

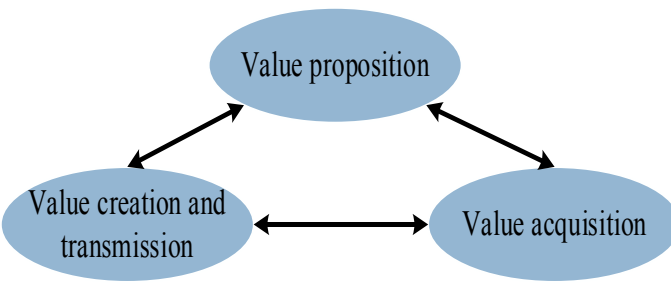

Figure 1. B2C e-commerce business model value triangle model. Source: constructed by author. 


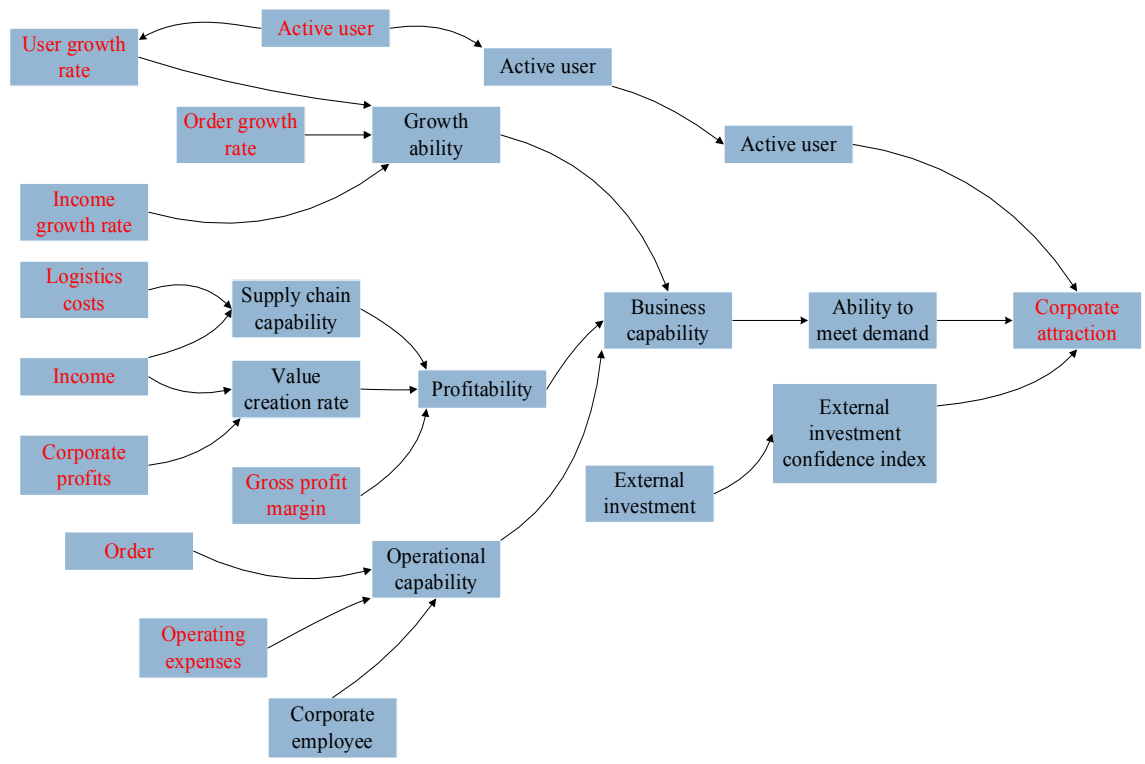

Figure 2. Value creation and delivery subsystem. Source: constructed by author.

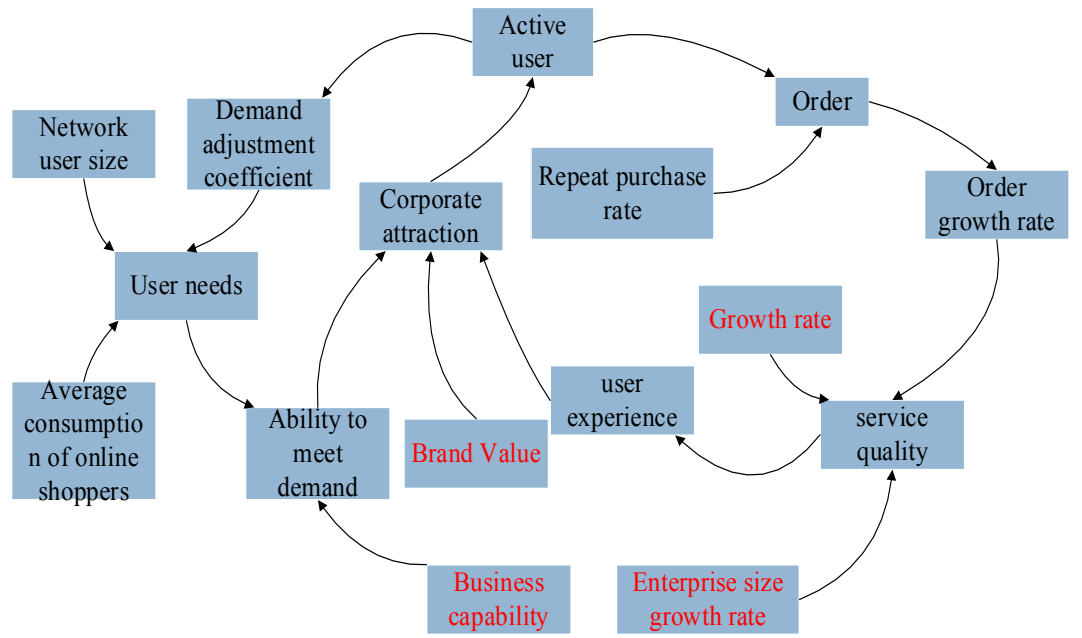

Figure 3. Value claims subsystem. Source: constructed by author.

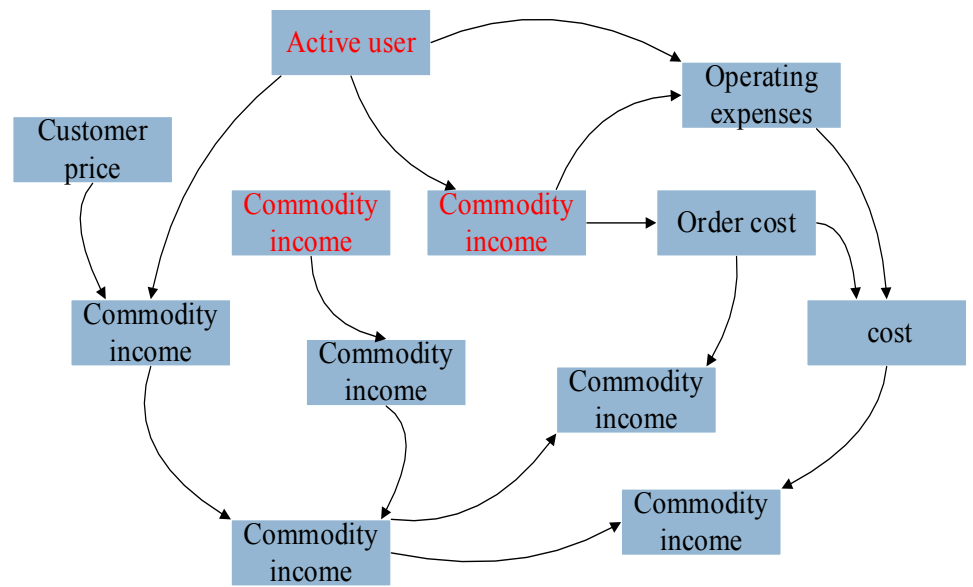

Figure 4. Value acquisition subsystem. Source: constructed by author. 
Table 1. Description of each subsystem and its elements.

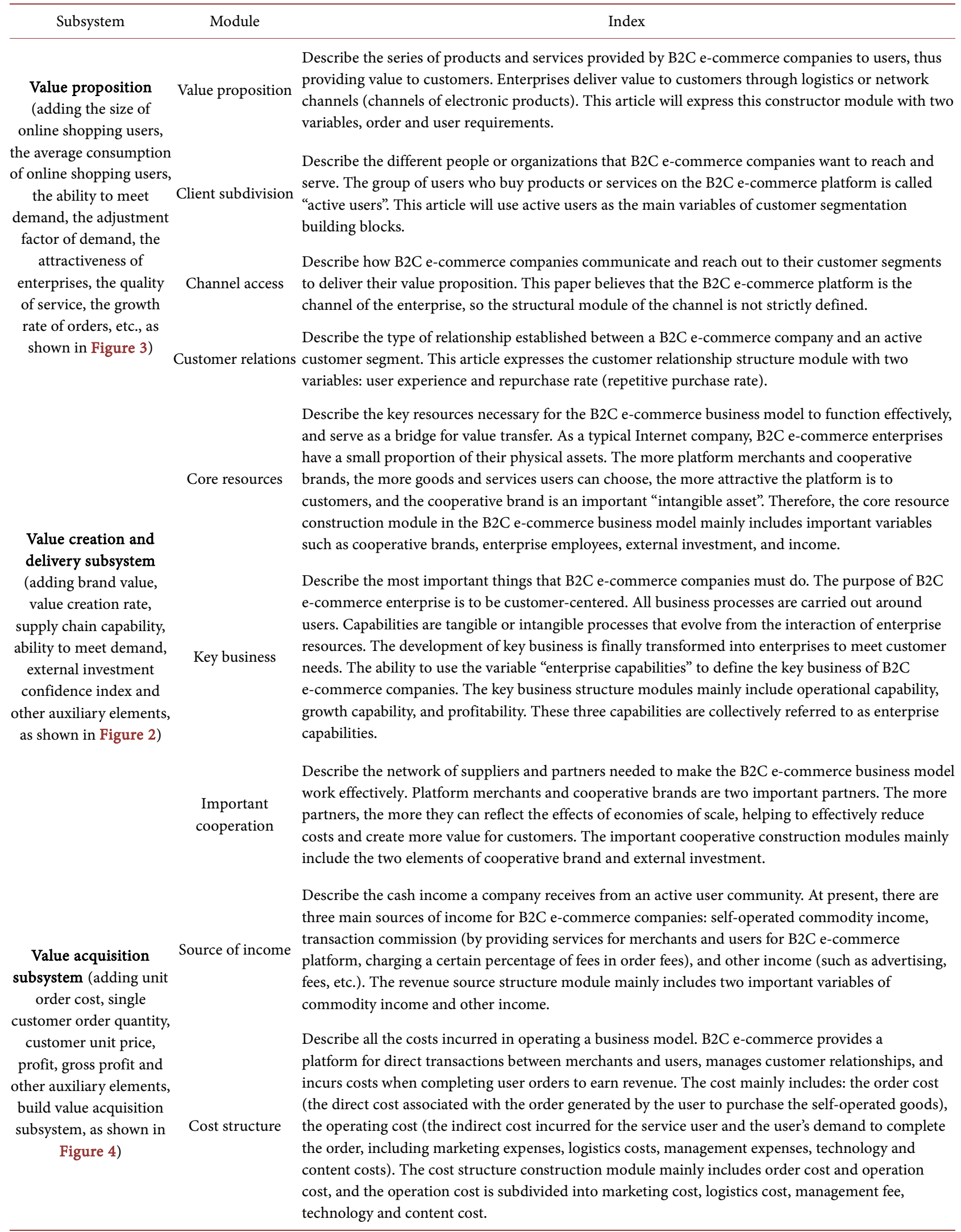

Source: New Generation Business Mode [8]. 
constructs a dynamic model of B2C e-commerce business model by means of system dynamics, and analyzes the relationship between sub-elements and other elements (including other subsystems) in these subsystems. The simulation software Vensim PLE was used to study the value creation process and dynamic change characteristics among the three subsystems, the causal circuit diagram was drawn and the corresponding conceptual model was established. The feedback structure of the system includes 35 feedback links. Then, based on the causal loop diagram, the system's stock, flow and auxiliary variables, and the causal loop of these variables are determined. The stock flow graph of its dynamic model was drawn (Figure 5). There are 52 variables in the model of the stock flow graph, including 5 state variables, 5 rate variables, 40 auxiliary variables and 2 constant variables. Further, the system dynamics equation is established by determining the state variable equation (integration operation), the rate variable equation (control of the system real logistics), and the auxiliary variable equation in the stock flow graph.

To further examine the system behavior, correctness of the model is verified by comparing with the actual data. The simulation settings include: 1) simulation object: Vipshop; 2) simulation time: 2009-2015, a total of 7 years; 3) simulation software: Vensim PLE; 4) simulation data source: Vipshop (China) Co., Ltd. Financial Annual Report (Accounting Standard: GAAP), iResearch Consulting E-Commerce Research Report, China E-Commerce Research Center, China E-Commerce Annual Report.

Numerical data, written data and subjective data need to be processed. The linear regression equation method and the nonlinear regression equation method in econometrics are used to predict the parameters of the $\mathrm{B} 2 \mathrm{C}$ e-commerce business model dynamics model. For example, the parameter between the customer

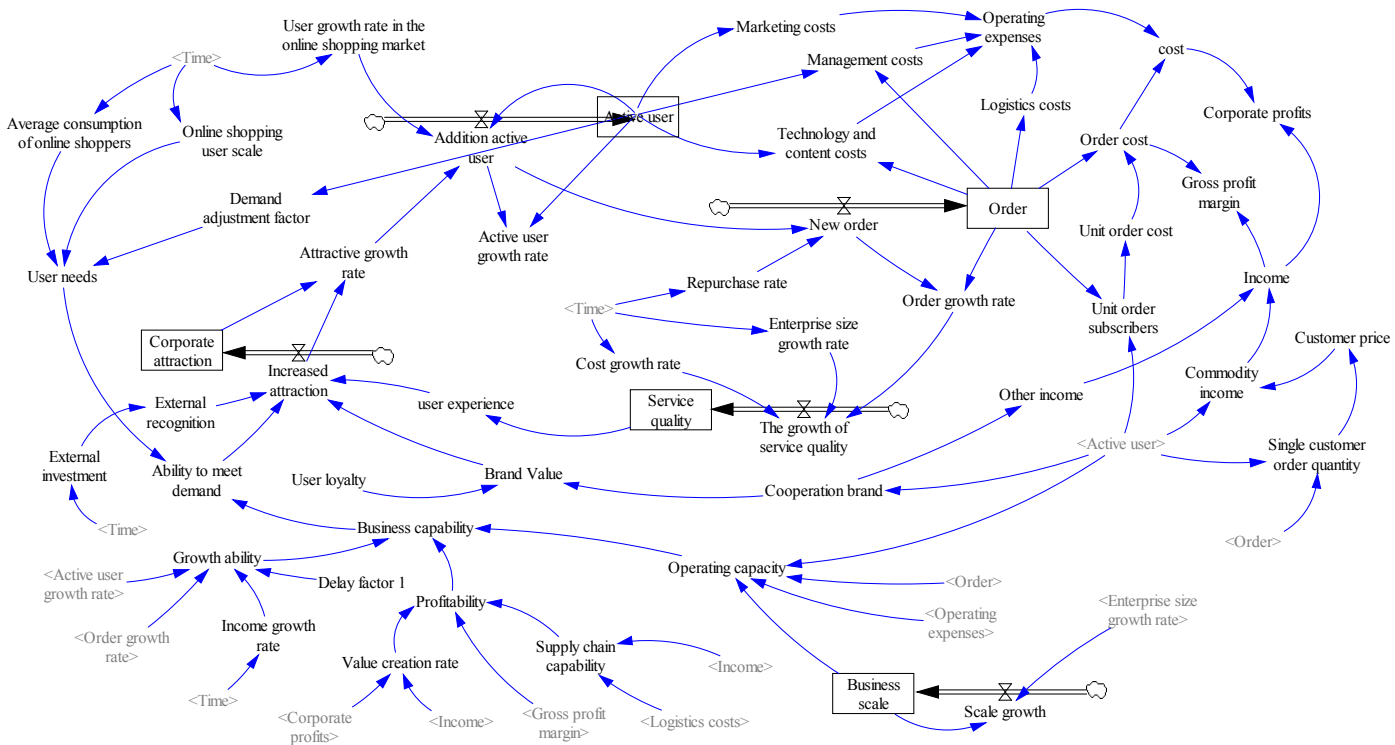

Figure 5. B2C e-commerce business model dynamics model inventory flow chart. Source: constructed by author. 
unit price $(Y)$ and the single customer order quantity $(X)$ is obtained by the linear regression equation method. The same method is used to obtain the unit order cost $(Y)$ and the unit order user number $(X)$ parameters. The parameters of management fee $(Y)$ and active user $(X 1)$ and order $(X 2)$ are obtained by nonlinear regression equation method. In the study of some elemental relationships and quantitative analysis, previous research results have been borrowed. For example, by referring to the dynamics model of the Internet of Things business model [20] in Dong Shuang (2006) and Li Yuying (2013), this paper defines user demand $(Y)$ by the average consumption of online shopping users $(X 1)$, online shopping user scale $(X 2)$, demand adjustment The coefficient $(X 3)$ affects the three variables and thus determines the parameters of the equation.

\subsection{Validity Testing}

1) Extreme Condition Test: The extreme condition test is carried out by direct inspection of the model equation and by simulation. The direct inspection refers to checking whether the variable equation and dimension of the model are in line with the reality based on the analysis of relevant data. The simulation run refers to whether the response of the model is reasonable when testing the extreme values of each input variable individually and jointly. The simulation run refers to whether the response of the model is reasonable when testing the extreme values of each input variable individually and jointly. Through repeated examinations, the variable equations and dimensions are consistent with the real system, and extremes such as cost and income variables (such as unit order cost, order cost, cost, management fee, logistics cost, etc.), active users, orders, etc. Under the conditions of the simulation, the performance of the model is in line with reality.

2) Behavioral Reproduction Test: The analysis of the financial statements published by Vipshop, the analysis report of B2C e-commerce industry (source: iResearch), and Vipshop case (source: iResearch). According to EBMO building blocks, and Vipshop financial report, six variables, income, cost, commodity income, order cost, active user and order are selected as behavioral recurrence test variables. R2 is used to test the fitting goodness (Table 2).

3) Behavioral Test: The behavioral test includes behavioral abnormality test and amazed behavioral test to test the limitations of the data and ensure the stability of the system behavior. The behavioral abnormality test tests whether the model will behave abnormally by deleting or modifying a relationship. In this way, the importance of these structures is examined, mainly using loop interruption

Table 2. Determination coefficient R2 value of key variables.

\begin{tabular}{ccccccc}
\hline Variables & Income & Cost & Commodity income & Order cost & Active user & Order \\
\hline $\begin{array}{l}\text { Measurement } \\
\text { coefficient R } \mathrm{R}^{2}\end{array}$ & 0.99952 & 0.99934 & 0.99943 & 0.99932 & 0.99339 & 0.9965 \\
\hline
\end{tabular}

Source: by author. 
analysis. The amazed behavioral test is to observe the behavior of variables in the model and to hunt down all sources of unanticipated or abnormal behavior. Through loop analysis of key variables and repeated observation of variable behavior, the model found no abnormal behavior, and its system behavior is in line with the reality.

4) Sensitivity Test: To analyze the influence degree of variables, equations or structures on system behavior. Numerical sensitivity test is used. By changing the parameters of variables such as demand adjustment coefficient, firm size, user loyalty, etc., the effects of these variables on system behavior are tested. It is found that when these variables are changed, the other variables of the model do not change drastically, and the system behavior of the model. There have been no major changes, so this paper considers the variables of the model to be valid.

\subsection{Main Feedback Analysis}

This paper uses the cause tree analysis (listing the variables that act on the specified variables layer by layer) and the result tree analysis (listing the effects of the variables on other variables layer by layer) to analyze the key variables that affect the value creation process of the $\mathrm{B} 2 \mathrm{C}$ e-commerce business model dynamics model systematically.

1) Active user feedback analysis

For the $\mathrm{B} 2 \mathrm{C}$ e-commerce platform, active users bring orders, in order to attract potential users and meet user needs, the platform generates costs, and the platform earns revenue by completing orders. When meeting user needs and completing orders, companies have increased their capabilities, improved their ability to meet user needs, and attracted more users. This feedback link can be briefly described as: active user $\rightarrow$ order $\rightarrow$ cost (income) $\rightarrow$ enterprise ability $\rightarrow$ ability to meet demand $\rightarrow$ active user. Based on this feedback, detailed analysis was performed using causal trees.

The Formation of New Active User: By analyzing the reason tree of new active users, active users are divided into external and internal growth. External growth is the growth of online shopping users, and internal growth is an active user attracted by enterprises. With the development of the online shopping market, enterprises have obtained online shopping users. B2C e-commerce companies attract potential users through channel sinking and customer marketing. By focusing on refined operations, the company creates superior categories, expands new categories, operates efficiently and enhances user experience, and improves the ability to meet user needs, enabling potential users. Become an active user.

The Function of Active User: Active users are the core elements of the B2C e-commerce business model. They are the basis for companies to obtain orders, generate costs, generate revenue, and form a sustainable source of competitiveness. This result tree reflects the $\mathrm{B} 2 \mathrm{C}$ e-commerce business model as "user-centric", and users are the key influencing factors for B2C e-commerce competition and development. In the business model, users are the key factor in val- 
ue proposition activities, important participants in value creation activities and delivery, and the source of value acquisition.

Active users buy products and services on the B2C e-commerce platform, and the company gets the order; In order to complete the order, the company must complete the logistics distribution system, and in order to attract and retain users and meet the needs of users, it also generates marketing, management, technical support (R\&D) activities, which trigger marketing expenses, management fees, and technology and content fees. At the same time, B2C e-commerce companies obtain commodity revenue by completing enterprise orders, and the platform attracts brand merchants/merchants through active users and third-party income by providing services to brand merchants/merchants, which form the income of the enterprises. The process of attracting and retaining users, satisfying users' needs and fulfilling user orders is the process of business operation. Through continuous cycle and continuous operation, the company has the ability to grow and operate; the income generated by active users and the costs incurred have an impact on the profitability of the company, and the role of active users in other variables is shown in Figure 6.

2) Order feedback analysis

The Formation of New Order: There are two sources for new orders: new orders for new users to purchase products and services, duplicate purchases for existing users, and two new variables: active users and repurchase rates are important factors influencing new orders. With the development of the online shopping market, the $\mathrm{B} 2 \mathrm{C}$ e-commerce platform enables the platform to open up new users and increase orders by satisfying user needs and adopting various customer marketing methods. In addition, the refinement and efficient operation of the platform, the creation of superior categories, and the expansion of new categories enhance the user experience, improve the ability to meet user needs, and increase the repeated purchases of existing users.

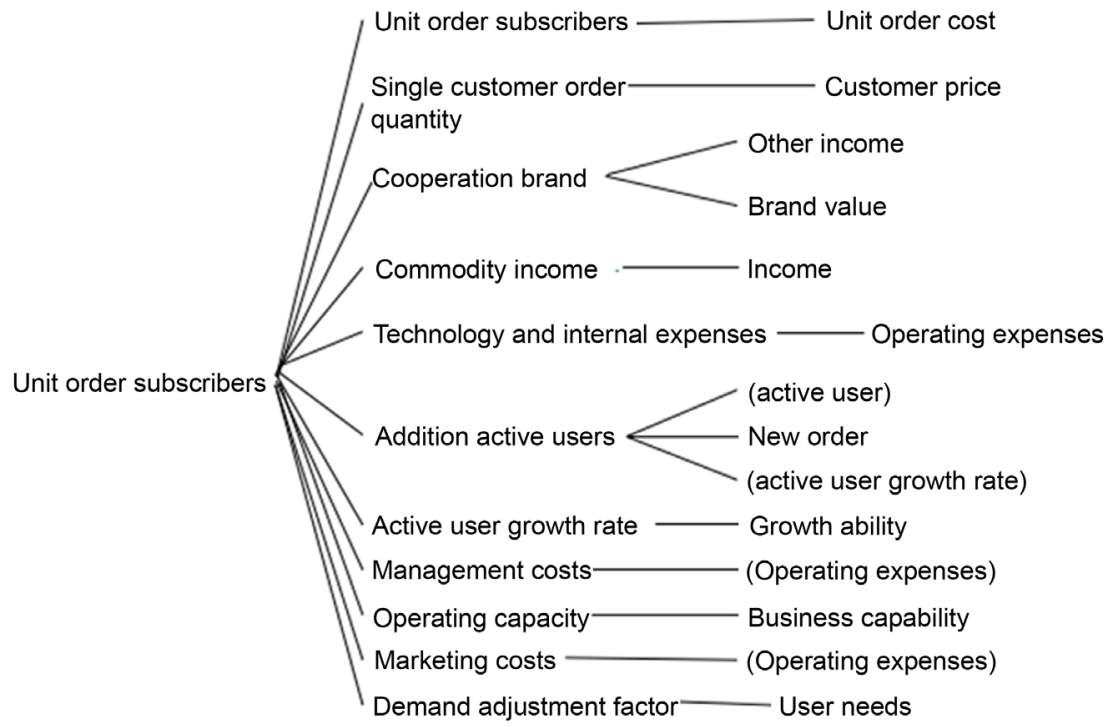

Figure 6. The role of active users on other variables. 
The Role of the Order: Orders are an important factor in B2C e-commerce business model, and are an important source of cost and revenue. The growth of orders has enabled B2C e-commerce platform to strengthen bargaining power with suppliers and reduce unit order costs to create more value for users. When users purchase products and services, the B2C e-commerce platform will incur costs, and the goods and services in the order will cause the order cost. In order to complete the user's order, the B2C e-commerce platform needs to establish a warehousing and logistics distribution system, maintain the operation system and manage the customer relationship, and implement management activities for the employees of the enterprise, thus generating logistics costs, management costs, technology and content costs are generated as part of operating costs. Orders bring revenue to $\mathrm{B} 2 \mathrm{C}$ e-commerce companies. The increase in orders will attract merchants/brands. The platform will obtain other income by providing services to merchants/brands. These are the sources of income for the company. The growth rate of orders will affect the service quality growth of B2C e-commerce platform, and the faster the order growth, the $\mathrm{B} 2 \mathrm{C}$ e-commerce platform needs to increase operating expenses, recruit more talents to meet user needs and complete user orders. The impact of orders on corporate capabilities is similar to the impact of users on corporate capabilities. The various business activities that the platform accomplishes when it meets user needs and completes orders are part of the formation of corporate capabilities as shown on Figure 7.

3) Analysis of enterprise capability feedback

Formation of Corporate Capabilities: The ability of an enterprise is mainly composed of operational capability, profitability and growth capability. B2C e-commerce companies need to cooperate with various corporate activities to attract and retain users, meet user needs and complete orders, and form operational capabilities; with the growth of active users and orders, the income earned

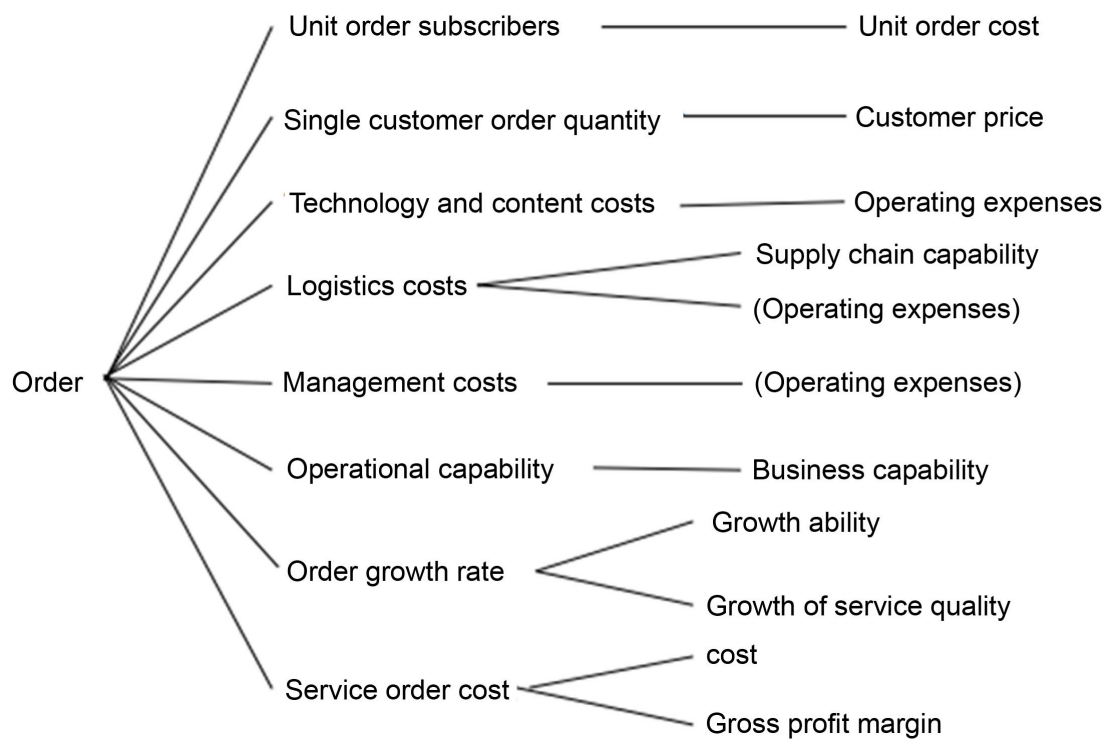

Figure 7. The effect of the order on other variables. 
by enterprises is also growing. This process has formed the growth capacity of enterprises and has been growing to cope with fierce market competition; B2C e-commerce companies attract users and complete orders, which will lead to cost and income. The company's gross profit and profits have an important impact on profitability.

The Role of Corporate Capabilities: Corporate capabilities include operational capabilities, growth capabilities, and profitability. Corporate capabilities are the foundation for a company's refined and efficient operations, and are the foundation for meeting user needs and attracting potential users. Operational capability is the basis for $\mathrm{B} 2 \mathrm{C}$ e-commerce companies to attract and retain users and meet the individual needs of users. It is also the basis for enterprises to provide value proposition and create and transfer value; growth ability makes the B2C e-commerce platform survive in the fierce market competition and is an important factor for sustainable development; Profitability is an important criterion for measuring the success of $\mathrm{B} 2 \mathrm{C} \mathrm{e-commerce} \mathrm{platform,} \mathrm{a} \mathrm{source} \mathrm{of} \mathrm{motiva-}$ tion for corporate sustainability, and the basis for companies to obtain value.

4) Analysis of income and cost feedback

Feedback Analysis of Revenue: B2C e-commerce companies earn revenue by meeting orders from users. There are two sources of income: commodity income and other income. Commodity income is the cash income obtained by $\mathrm{B} 2 \mathrm{C}$ e-commerce enterprises featuring "self-operated + platform" to meet user needs and complete user orders; other income is the revenue generated by the platform to provide services to merchants/brands, including transaction commissions and advertising fees. Revenue is the embodiment of B2C e-commerce enterprise to create value for customers by creating value for customers. It is an important manifestation of profitability. Revenue growth is also an important manifestation of the growth ability of B2C e-commerce platform.

Cost Feedback Analysis: When the B2C e-commerce platform attracts and retains users, meets user needs, and completes user orders, it triggers various corporate activities, resulting in operational and order costs. The cost component consists of two parts: the order cost (the direct cost associated with the order generated by the user to purchase the self-operated goods) and the operating expenses (the indirect costs incurred to service the user and satisfy the user's needs to complete the order). Cost affects gross profit and profit, which affects the profitability of the enterprise; logistics expenses (visual cost) have an important impact on supply chain capacity as an important part of operating expenses; Operational activities such as marketing, logistics, management, technology and content involved in operating expenses have an important impact on the operational capabilities of the company.

\section{Result of Simulation}

Year data from 2009 to 2015 is used as input in the model with a time interval of 1 year. Through the simulation data of the key 6 variables and the original data 
comparison table (Table 3), the simulation prediction errors of the four variables are less than 5\%, and the prediction errors of the other two variables are less than $7 \%$ and $9 \%$. The accuracy rate of the key variables is at least $90 \%$. On top of that, the overall Mean Square Error is 0.018. Therefore the simulation results of these key variables have small prediction errors.

For impact of the change of the variable on the system behavior in the future, this paper selects the demand adjustment coefficient, user loyalty, enterprise scale growth rate, and brand cooperation policy as adjustment conditions. The variable parameters remain unchanged in 2009-2015 (historical data period), and the parameters of the 2016-2020 variables are adjusted. The impact of different assignments of these three variables on the behavior of the system over a period of time was studied, and the impact of these changes on business development as well.

1) The impact of changes in demand adjustment factors on system behavior

According to the demand adjustment factor, the original parameter value is 0.25 , which shows the impact of the demand adjustment of active users in the B2C e-commerce business model on the whole model. The parameters of the demand adjustment coefficient are $0.25,0.3$ and 0.35 for 2016-2020, respectively. The simulation analysis of the e-commerce business model system dynamics model obtains the data values of the $\mathrm{B} 2 \mathrm{C}$ e-commerce enterprises each year. The

Table 3. Comparison of simulation data of key variables in the model with original data.

\begin{tabular}{|c|c|c|c|c|c|c|c|c|c|}
\hline \multirow{2}{*}{ Years } & \multicolumn{3}{|c|}{ Income (ten thousand yuan) } & \multicolumn{3}{|c|}{ Cost (ten thousand yuan) } & \multicolumn{3}{|c|}{ Active users (ten thousand) } \\
\hline & Simulation value & Actual value & Fit & Simulation value & Actual value & Fit & Simulation value & Actual value & Fit \\
\hline 2009 & 1880.3 & 1911.89 & $98.35 \%$ & 2909.19 & 2901.17 & $100.28 \%$ & 3.8 & 3.8 & $100 \%$ \\
\hline 2010 & $21,511.3$ & $21,502.8$ & $100.04 \%$ & 26,987 & $27,075.1$ & $99.67 \%$ & 27.25 & 27.6 & $98.73 \%$ \\
\hline 2011 & 143,280 & $142,959.6$ & $100.22 \%$ & 158,477 & 164,808 & $96.16 \%$ & 147.8 & 149 & $99.19 \%$ \\
\hline 2012 & 440,249 & $431,191.5$ & $102.1 \%$ & 453,243 & 440,233 & $102.96 \%$ & 428.41 & 411 & $104.24 \%$ \\
\hline 2013 & $1,053,210$ & $1,027,113$ & $102.54 \%$ & $1,046,870$ & 999,801 & $104.71 \%$ & 1009.9 & 944 & $106.98 \%$ \\
\hline 2014 & $2,267,760$ & $2,341,399$ & $96.85 \%$ & $2,207,060$ & $2,272,595$ & $97.12 \%$ & 2165.71 & 2360 & $91.77 \%$ \\
\hline 2015 & $4,044,390$ & $4,020,321$ & $100.6 \%$ & $3,877,750$ & $3,844,109$ & $100.88 \%$ & 3849.62 & 3660 & $105.18 \%$ \\
\hline \multirow{2}{*}{ Years } & \multicolumn{3}{|c|}{ Commodity income (ten thousand yuan) } & \multicolumn{3}{|c|}{ Order cost (ten thousand yuan) } & \multicolumn{3}{|c|}{ Order (ten thousand) } \\
\hline & Simulation value & Actual value & Fit & Simulation value & Actual value & Fit & Simulation value & Actual value & Fit \\
\hline 2009 & 1880.3 & 1911.89 & $98.35 \%$ & 1769.07 & 1761.6 & $100.42 \%$ & 7.1 & 7.1 & $100 \%$ \\
\hline 2010 & $21,511.3$ & $21,502.8$ & $100.04 \%$ & $19,050.9$ & $19,384.2$ & $98.28 \%$ & 100.77 & 92.7 & $108.71 \%$ \\
\hline 2011 & 142,903 & $142,424.66$ & $100.34 \%$ & 114,075 & $115,681.9$ & $98.61 \%$ & 709.5 & 726.9 & $97.61 \%$ \\
\hline 2012 & 438,380 & $429,914.28$ & $101.97 \%$ & 340,941 & 334,955 & $101.79 \%$ & 2205.43 & 2191.9 & $100.62 \%$ \\
\hline 2013 & $1,046,460$ & $1,017,360.6$ & $102.86 \%$ & 808,171 & 780,261 & $103.58 \%$ & 5282.84 & 4915.9 & $107.46 \%$ \\
\hline 2014 & $2,246,540$ & $2,296,434.1$ & $97.83 \%$ & $1,734,100$ & $1,759,196$ & $98.57 \%$ & 11,344 & 11,800 & $96.14 \%$ \\
\hline 2015 & $3,994,040$ & $3,940,996$ & $101.35 \%$ & $3,082,730$ & $3,030,672.3$ & $101.72 \%$ & 20,169 & 19,310 & $104.45 \%$ \\
\hline
\end{tabular}

Note: The simulation data retains at most two decimal places; the fitness represents the percentage of the simulated value to the actual value. 
growth of the four key variables of active users, orders, revenue, and cost is shown in Figure 8.

From Table 4, we can see that when the parameter of the demand adjustment coefficient increases by 0.05 , the four key variables decrease and the decrease rate increases continuously, and the change trend is basically similar. The reduction in costs is slower than the reduction in revenue and reduces corporate profits. When the parameter of the demand adjustment factor increases by 0.1 , the

Table 4. Comparison of the influence of parameters of different demand adjustment factors on key variables.

\begin{tabular}{|c|c|c|c|c|c|c|}
\hline \multicolumn{2}{|l|}{ Time (year) } & 2016 & 2017 & 2018 & 2019 & 2020 \\
\hline \multirow{4}{*}{$\begin{array}{l}\text { The parameter of the } \\
\text { demand adjustment } \\
\text { factor is } 0.3\end{array}$} & income & 0 & $-7.9 \%$ & $-14 \%$ & $-18.3 \%$ & $-21.7 \%$ \\
\hline & cost & 0 & $-7.7 \%$ & $-13.6 \%$ & $-17.8 \%$ & $-21.2 \%$ \\
\hline & active user & 0 & $-7.8 \%$ & $-13.8 \%$ & $-18.1 \%$ & $-21.4 \%$ \\
\hline & order & 0 & $-7.9 \%$ & $-13.9 \%$ & $-18.1 \%$ & $-21.5 \%$ \\
\hline \multirow{4}{*}{$\begin{array}{l}\text { The parameter of the } \\
\text { demand adjustment } \\
\text { factor is } 0.35\end{array}$} & income & 0 & $-13 \%$ & $-22.6 \%$ & $-29.2 \%$ & $-34.5 \%$ \\
\hline & cost & 0 & $-12.7 \%$ & $-22 \%$ & $-28.5 \%$ & $-33.7 \%$ \\
\hline & active user & 0 & $-12.9 \%$ & $-22.3 \%$ & $-28.9 \%$ & $-34.1 \%$ \\
\hline & order & 0 & $-12.9 \%$ & $-22.4 \%$ & $-29 \%$ & $-34.2 \%$ \\
\hline
\end{tabular}

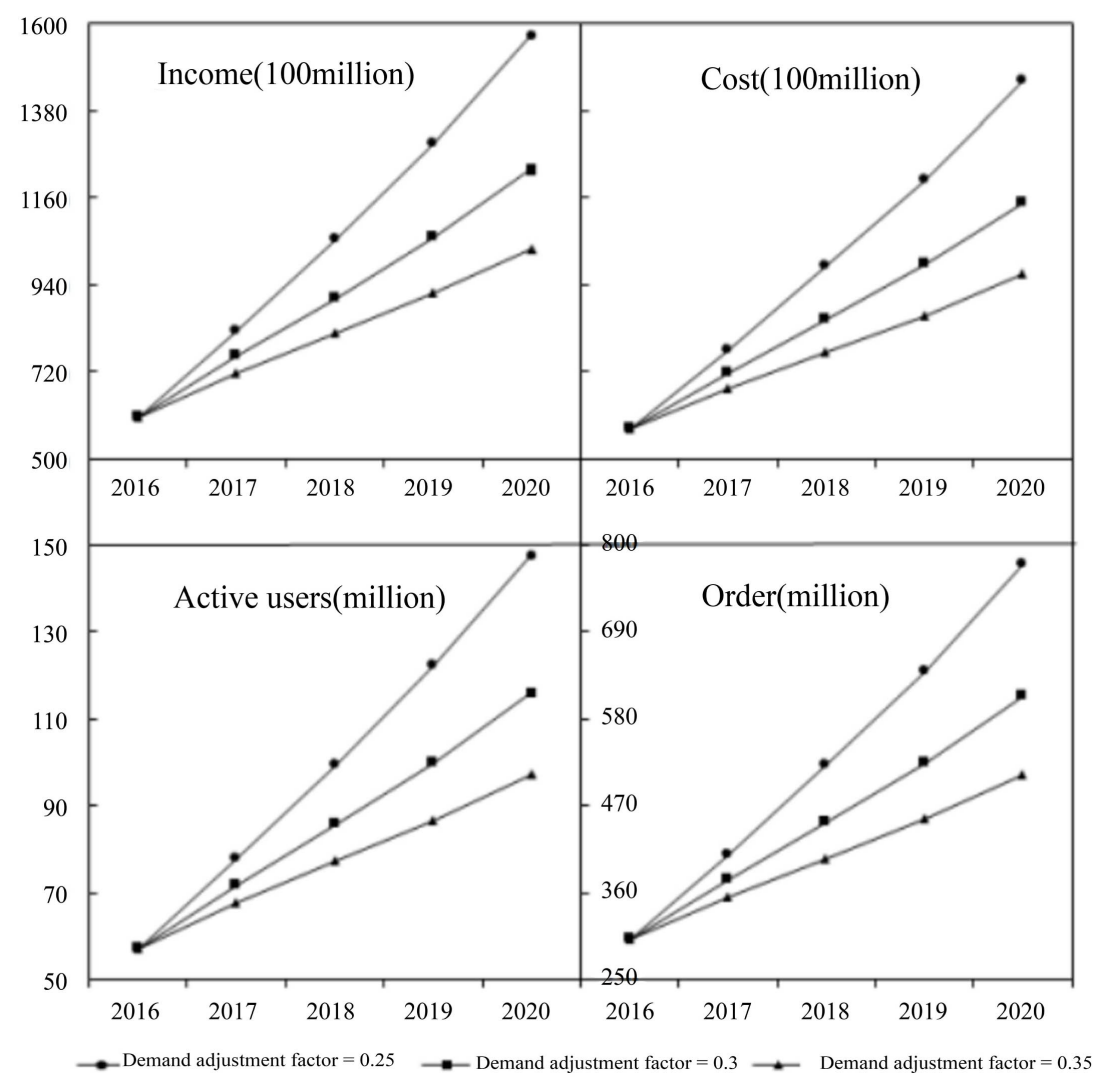

Figure 8. Change in key variables when the parameters of the demand adjustment factor change. 
overall trend is similar to the trend when the parameter increases by 0.05 . Therefore, active users are the core elements of the $\mathrm{B} 2 \mathrm{C}$ e-commerce business model model, and changes in user requirements have an important impact on the behavior of the model. The expansion of user demand while maintaining other conditions, results in a decline in revenue, costs, active users, and orders. And it indicates that the expansion of user demand requires enterprises to provide more product selection, optimize operational efficiency, and provide better service quality and user experience and meet user needs and create more value for users.

2) The impact of changes in user loyalty on system behavior

B2C e-commerce companies enhance customer value by creating a good shopping experience for customers. A good user experience can enhance user loyalty, thereby increasing users' repeated purchases and word-of-mouth communication. This paper studies the impact of user loyalty on B2C e-commerce enterprises. The user loyalty is set to $0.6,0.7$ and 0.8 respectively, and the experimental data is obtained by running the system dynamics model. Through data comparison, the impact of changes in user loyalty on the key variables of the model is analyzed, and the impact of changes in user loyalty on the development of $\mathrm{B} 2 \mathrm{C}$ e-commerce enterprises is measured. The changes of key variables are shown in Figure 9.

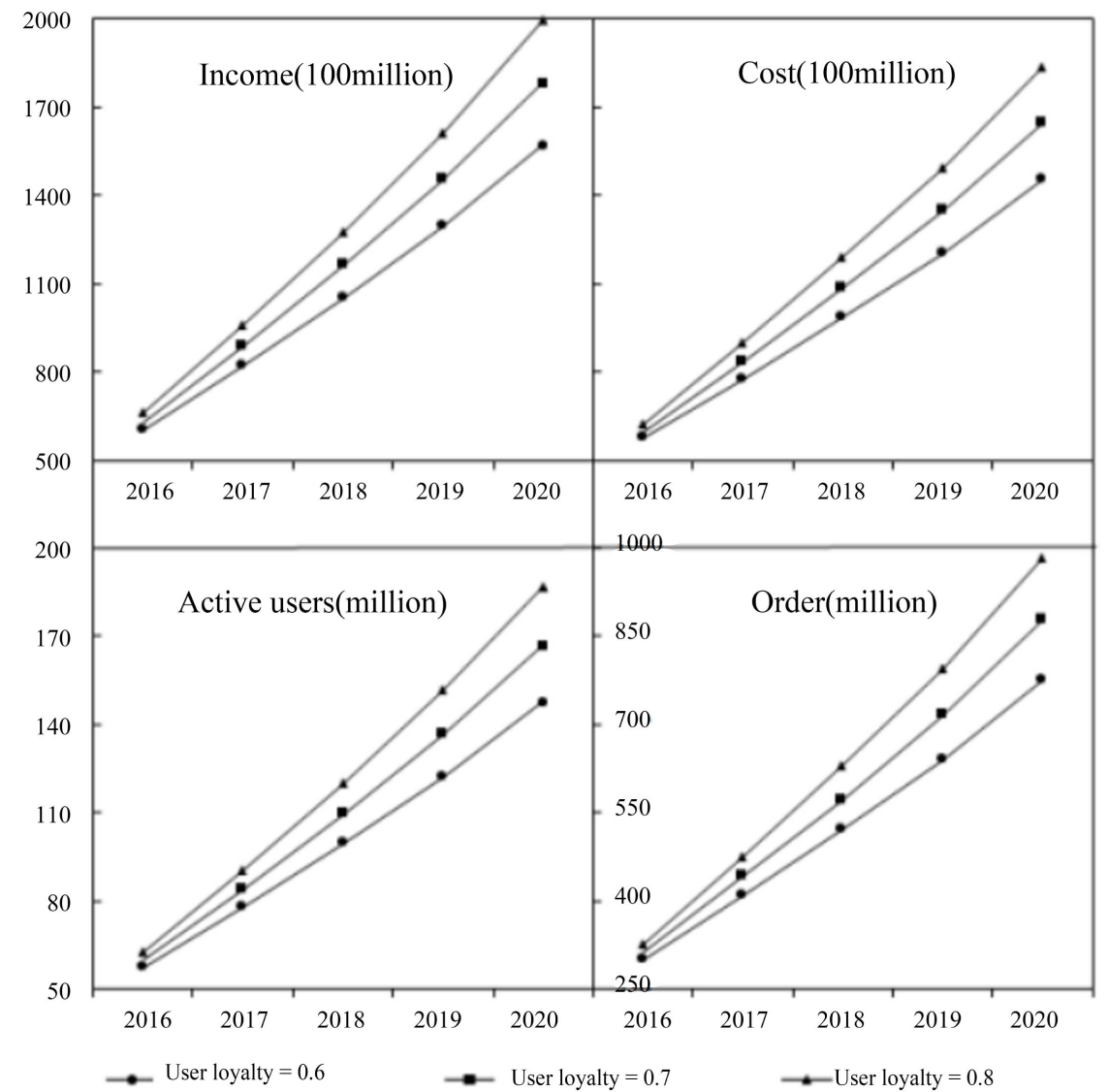

Figure 9. Key variable growth graph when user loyalty changes. 
As shown in Table 5, when user loyalty is increased to 0.7 , the key variables are increasing, in which the trend of active users and costs is similar, and the trends of orders and income are similar. Specific analysis, user loyalty has increased repeat purchases, order volume and revenue. The increased orders have enabled the platform to have stronger bargaining power, reduced purchase costs, and created more value for users. And it also brought more profit to the company. When user loyalty increased to 0.8 , the overall change in the model was consistent with the increase in user loyalty to 0.7. In summary, users are the focus of B2C e-commerce competition and the source of sustainable development. User loyalty is to bring word-of-mouth marketing and repeat purchases to enterprises. The current loyalty of B2C e-commerce platform can further enhance the space. The focus of future e-commerce competition is no longer limited to price, but rather to a better experience for customers.

3) The impact of changes in the growth rate of the company on system behavior

Enlarging the scale of the enterprise can better serve the users and meet the needs of users. It is necessary to study the impact of the growth of the enterprise on the development of B2C e-commerce enterprises. From 2016 to 2020, the growth rate of controlling the scale of enterprises is $0.5,0.35,0.2,0.1,0.1$, the first group growth rate is $0.6,0.5,0.4,0.3,0.2$, and the second group growth rate is $0.65,0.6,0.55 .0 .5,0.45$, the running model obtained experimental comparison data, as shown in Figure 10.

Table 6 shows the change in the growth rate of key variables when the growth rate of the company's scale is different. When the growth rate of the enterprise is set to the growth rate of the first group, the variables increase year by year. The growth of the first three years (2016-2018) is not obvious, and the latter two years (2019-2020) have improved. The trends of the four variables are similar, and the growth of income and cost is not much different. The increase in the size of the company does not bring about a significant increase in profits. The growth rate of the second group is similar to that of the first group. The growth rate of the second group is significantly higher than that of the first group, however,

Table 5. Comparison of the impact of different user loyalty on key variables.

\begin{tabular}{|c|c|c|c|c|c|c|}
\hline \multicolumn{2}{|c|}{ Time (year) } & 2016 & 2017 & 2018 & 2019 & 2020 \\
\hline \multirow{4}{*}{ User loyalty is 0.7} & income & $4.6 \%$ & $8.1 \%$ & $10.4 \%$ & $12.0 \%$ & $13.3 \%$ \\
\hline & cost & $4.4 \%$ & $7.8 \%$ & $10.1 \%$ & $11.7 \%$ & $12.8 \%$ \\
\hline & active user & $4.5 \%$ & $8 \%$ & $10.3 \%$ & $11.8 \%$ & $13 \%$ \\
\hline & order & $4.5 \%$ & $8 \%$ & $9.8 \%$ & $11.9 \%$ & $13.1 \%$ \\
\hline \multirow{4}{*}{ User loyalty is 0.8} & income & $9.2 \%$ & $16.4 \%$ & $21.3 \%$ & $24.5 \%$ & $27 \%$ \\
\hline & cost & $8.9 \%$ & $15.9 \%$ & $20.6 \%$ & $23.7 \%$ & $26.1 \%$ \\
\hline & active user & $9.1 \%$ & $16.2 \%$ & $20.9 \%$ & $24.1 \%$ & $26.5 \%$ \\
\hline & order & $9.1 \%$ & $16.2 \%$ & $21 \%$ & $24.2 \%$ & $26.7 \%$ \\
\hline
\end{tabular}


Table 6. Comparison of the impact of different firm size growth rates on key variables.

\begin{tabular}{|c|c|c|c|c|c|c|}
\hline \multicolumn{2}{|l|}{ Time (year) } & 2016 & 2017 & 2018 & 2019 & 2020 \\
\hline \multirow{4}{*}{$\begin{array}{c}\text { The annual growth rate } \\
\text { of enterprises is } 0.6,0.5 \text {, } \\
0.4,0.3,0.2\end{array}$} & income & 0 & $1.1 \%$ & $3.6 \%$ & $7.8 \%$ & $14.0 \%$ \\
\hline & cost & 0 & $1.1 \%$ & $3.5 \%$ & $7.6 \%$ & $13.5 \%$ \\
\hline & active user & 0 & $1.1 \%$ & $3.6 \%$ & $7.7 \%$ & $13.7 \%$ \\
\hline & order & 0 & $1.1 \%$ & $3.6 \%$ & $7.8 \%$ & $13.8 \%$ \\
\hline \multirow{4}{*}{$\begin{array}{l}\text { The annual growth rate } \\
\text { of the enterprise scale is } \\
0.65,0.6,0.55,0.5,0.45\end{array}$} & income & 0 & $1.6 \%$ & $5.8 \%$ & $13.2 \%$ & $25.6 \%$ \\
\hline & cost & 0 & $1.6 \%$ & $5.6 \%$ & $12.8 \%$ & $24.8 \%$ \\
\hline & active user & 0 & $1.6 \%$ & $5.7 \%$ & $13 \%$ & $25.2 \%$ \\
\hline & order & 0 & $1.6 \%$ & $5.7 \%$ & $13.1 \%$ & $25.3 \%$ \\
\hline
\end{tabular}

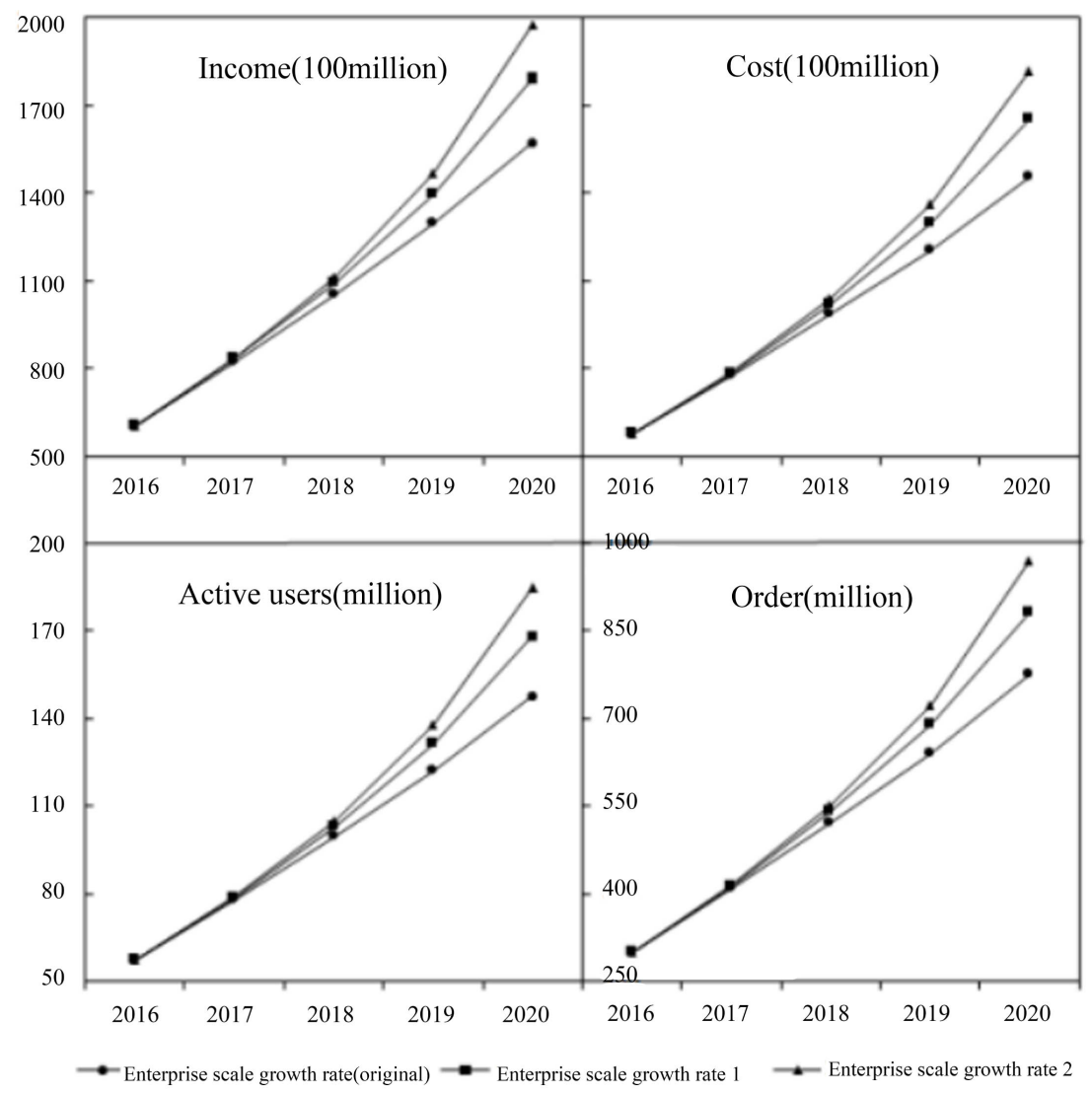

Figure 10. Growth curve of key variables when the growth of enterprise scale changes.

the variable growth of the second group growth rate did not significantly increase compared with the variable growth of the first group. The growth of the enterprise scale did not bring significant impact on the B2C e-commerce enterprise. In summary, B2C e-commerce enterprises have shifted from extensive development to refined development. In the past, the growth driven by enterprise scale growth has shifted to fine and efficient service to users and met user needs and complete user orders.

4) The impact of changes in brand cooperation policies on system behavior 
Setting the original value of the brand cooperation policy: the parameter of the cooperative brand $=47$, the coefficient of other income is 35,000 , changing the brand cooperation policy, strengthening the brand cooperation and reducing the brand service rate, brand cooperation policy 1 : cooperative brand parameters $=70.5$, other income coefficient is 52,500 , brand cooperation policy 2: cooperative brand parameters $=94$, other income coefficient is 70,000 , the running model is compared with the experimental group data, as shown in Figure 11. As can be seen from Table 7, when strengthening brand cooperation and reducing

Table 7. Comparison of the impact of different brand cooperation policies on key variables.

\begin{tabular}{ccccccc}
\hline \multicolumn{2}{c}{ Time (year) } & 2016 & 2017 & 2018 & 2019 & 2020 \\
\hline & income & $1.1 \%$ & $4.7 \%$ & $7.8 \%$ & $10.2 \%$ & $12.2 \%$ \\
$\begin{array}{c}\text { Brand Cooperation } \\
\text { Policy 1 }\end{array}$ & cost & 0 & $3.3 \%$ & $6.1 \%$ & $8.2 \%$ & $9.9 \%$ \\
& active user & 0 & $3.3 \%$ & $6.2 \%$ & $8.3 \%$ & $10.1 \%$ \\
Brand Cooperation & cost & 0 & $3.4 \%$ & $6.2 \%$ & $8.4 \%$ & $10.1 \%$ \\
Policy 2 & income & $2.2 \%$ & $9.4 \%$ & $15.8 \%$ & $20.7 \%$ & $25 \%$ \\
& active user & 0 & $6.4 \%$ & $12.1 \%$ & $16.4 \%$ & $20 \%$ \\
\hline
\end{tabular}

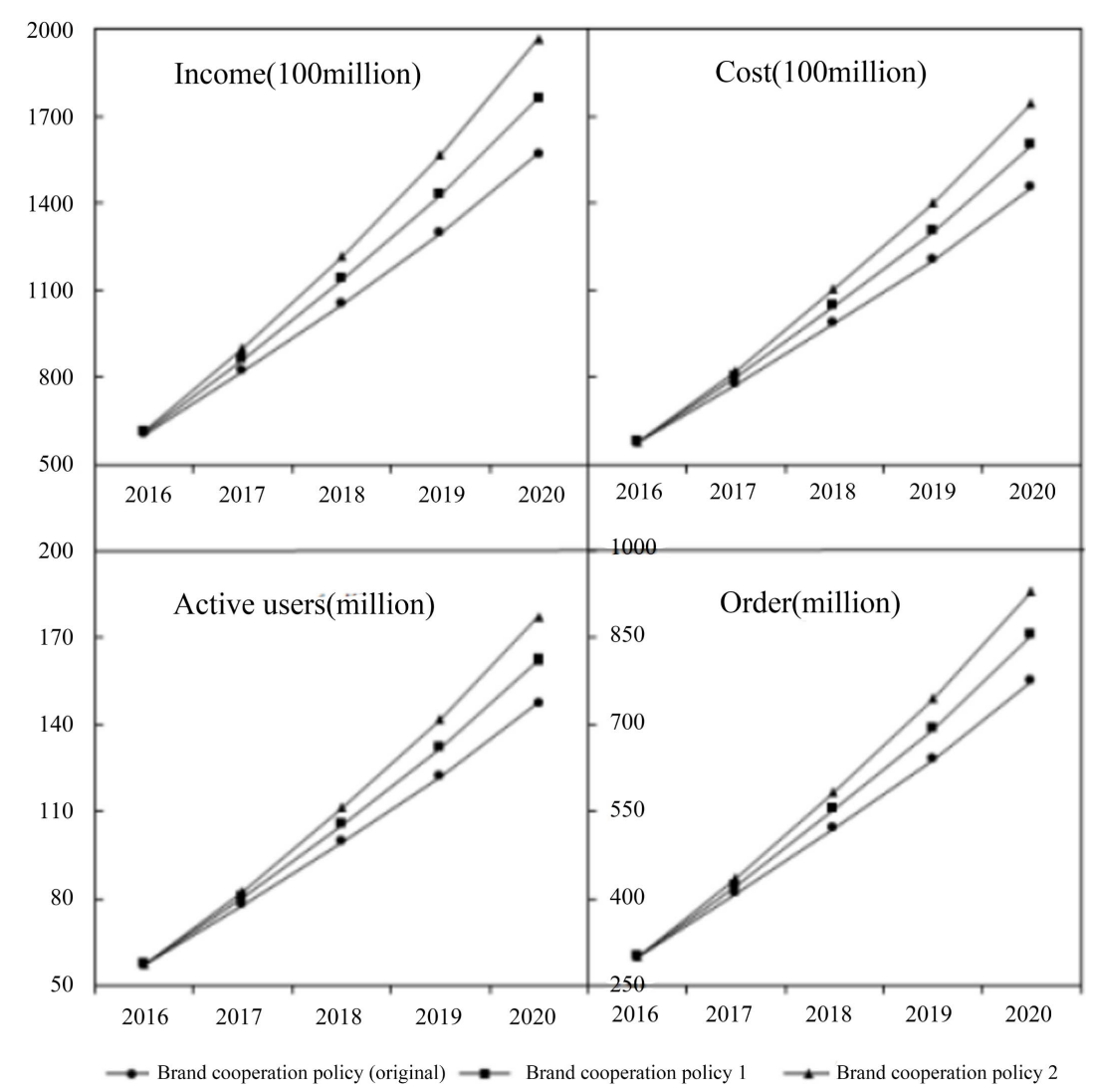

Figure 11. Key variable growth changes when brand cooperation policy changes. 
brand service rates, the key variables are all growth, which indicates that adopting the platform open strategy is conducive to the development of $\mathrm{B} 2 \mathrm{C}$ e-commerce enterprises. When adopting the brand cooperation policyl, the growth rate of income is higher than the increase of cost, active users and orders, which is mainly due to the increase of other income in the income source. Revenue is growing faster than cost, indicating that the implementation of an open platform strategy can increase corporate profits. Similarly, when the platform is further strengthened, that is, when the brand cooperation policy 2 is adopted, the results are similar to those of the policy 1 are obtained. Moreover, the gap between the increase in income and cost has further widened, that is, Policy 2 has further increased corporate profits.

Based on the above analysis, we have the following conclusions:

1) Active users are the basis for attracting brand cooperation. Active users are the basis of B2C e-commerce enterprise revenue. Only when the user's needs are met and orders are completed, B2C e-commerce enterprises can earn income and achieve sustainable development. At the same time, the growth of active users and operational activities that meets the needs of active users has an important impact on business capabilities.

2) User loyalty has an important impact on revenue and profit. User loyalty behavior can bring expected users, repeated purchase behavior and word-of-mouth communication. Increasing user loyalty has brought more active users and orders, creating more profits for the company; this effect is more pronounced when user loyalty is further improved.

3) The impact of enterprise scale growth on enterprise development is not significant. By increasing the scale of enterprise growth, the growth rate of revenue and cost is not much different. The scale of enterprise is faster than income growth, and there is no significant increase in profits. When the $\mathrm{B} 2 \mathrm{C}$ e-commerce market grows rapidly, B companies need to continuously expand their scale to cope with the rapidly growing market. When the growth trend of the online shopping market slows down, companies should focus on improving operational efficiency and implementing refined operations.

4) Brand cooperation and service rate have a significant impact on revenue and profit. Enterprises adopting a platform open strategy and reducing the service rate of brand owners will bring more active users and orders and third-party revenues, and corporate profits will increase. At the same time, increasing the platform opening strategy can further increase the profit growth.

\section{Conclusions}

Based on the logic of value creation, this paper deeply analyzes the components of $\mathrm{B} 2 \mathrm{C}$ e-commerce business model and the interrelationship between the elements, and draws on the EBMO e-commerce business model and the business model canvas (BMC) 9 building blocks to build the three subsystems of the model: value proposition, value creation and transmission, and value acquisi- 
tion. The system dynamics is used to analyze the qualitative and quantitative analysis of the model. The relationship between the three subsystems is studied in depth, and the value creation and dynamics of the model are explored. In order to find the key variables affecting the model, we look deeply into its value creation and process of change. Empirically, system dynamics is employed to simulate the process based on the well-known listed companies data. The main contribution of the paper is that, compared to traditional case study methods or theoretical analysis methods, this paper introduces the dynamics of $\mathrm{B} 2 \mathrm{C}$ e-commerce business model by system dynamics, which makes the $\mathrm{B} 2 \mathrm{C}$ e-commerce business model analyze for the first time from qualitative and quantitative perspectives.

The model proposed in this paper has made some progress in the research of B2C e-commerce business model, but due to the limited level and data range, there are still many shortcomings in the research of the thesis: 1) due to the complexity of the business model and the influence of internal and external factors, the actual situation is much more complicated than the model. Therefore, whether the model can fully simulate the e-commerce model other than $\mathrm{B} 2 \mathrm{C}$ remains to be further studied and tested; 2) the public data of B2C e-commerce enterprises are obtained in this paper; the selection of variables in the model is limited due to the acquisition of data, which can be compensated under certain data perfect conditions.

The future research will focus on test with more cases, where comparative studies may be feasible. In addition, the study will be more reliable if more financial data could be provided on top of limited public data.

\section{Acknowledgements}

This research is supported by Guangdong Province Philosophy and Social Sciences "13th Five-year Plan” (GD17CGL10).

\section{Conflicts of Interest}

The authors declare no conflicts of interest regarding the publication of this paper.

\section{References}

[1] Afuah, A. and Tucci, C. (2001) Internet Business Models and Strategies: Text and Cases. McGraw-Hill/Irwin, New York.

[2] Markides, C. and Charitou, C. (2004) Competing with Dual Business Models: A Contingency Approach. The Academy of Management Executive, 18, 22-36. https://doi.org/10.5465/ame.2004.14776164

[3] Cui, L.G. and Zhang, J.W. (2015) Conceptual Analysis and Research Perspective of Business Model. Journal of Management, 12, 1240-1247.

[4] Li, X.R., Zhang, X., Li, Z.X., et al. (2016) Bibliometric Analysis of Business Models. Systems Engineering. Theory \& Practice, 36, 273-287.

[5] Doganova, L. and Eyquem-Renault, M. (2009) What Do Business Models Do: In- 
novation Devices in Technology Entrepreneurship. Research Policy, 38, 1559-1570. https://doi.org/10.1016/j.respol.2009.08.002

[6] Wang, X.D. and Dong, D. (2013) Evaluation of Foreign Business Model Expression Model and Construction of Integrated Expression Model. Foreign Economics and Management, 35, 49-61.

[7] Osterwalder, A. and Pigneur, Y. (2004) An Ontology for E-Business Models. Value Creation from E-Business Models, 1, 65-97. https://doi.org/10.1016/B978-075066140-9/50006-0

[8] Osterwalder, A. and Pigneur, Y. (2010) Business Model Generation: A Handbook for Visionaries, Game Changers, and cHallengers. John Wiley \& Sons, Hoboken.

[9] Gordijn, J. and Akkermans, H. (2001) Designing and Evaluating E-Business Models. Intelligent E-Business, 16, 11-17. https://doi.org/10.1109/5254.941353

[10] Johnson, M., Christensen, C. and Kagermann, H. (2008) Reinventing Your Business Model. Harvard Business Review, 86, 50-59.

[11] Wei, W. and Zhu, W.X. (2009) Discovering Business Models. Mechanical Industry Press, Beijing.

[12] Achtenhagen, L., Melin, L. and Naldi, L. (2013) Dynamics of Business Models: Strategizing, Critical Capabilities and Activities for Sustained Value Creation. Long Range Planning, 46, 427-442. https://doi.org/10.1016/j.lrp.2013.04.002

[13] Hamel, G. (2000) Leading the Revolution. Havard Business School Press, Boston.

[14] Osterwalder, A., Pigneur, Y. and Tucci, C. (2005) Clarifying Business Model: Origins Present and Future of the Concept. Communications of the Association for Information Science, 16, 1-25. https://doi.org/10.17705/1CAIS.01601

[15] Yuan, L. (2007) Reconstruction of Business Model System. China Industrial Economy, 70-79.

[16] Willenstein, L., Valk, T. and Meeus, M. (2007) Dynamics in Business Models: An Empirical Analysis of Medical Biotechnology Firms in the Netherlands. Technovation, 27, 221-232. https://doi.org/10.1016/j.technovation.2006.08.005

[17] Zhang, J.W. and Wang, Y.J. (2010) Research on Business Model Concept Model Based on Value Triangle Logic. Foreign Economics and Management, 32, 1-8.

[18] Demil, B. and Lecocq, X. (2010) Business Model Evolution: In Search of Dynamic Consistency. Long Range Planning, 43, 227-246. https://doi.org/10.1016/j.lrp.2010.02.004

[19] Yip, G. (2004) Using Strategy to Change Your Business Model. Business Strategy Review, 15, 17-24. https://doi.org/10.1111/j.0955-6419.2004.00308.x

[20] Dong, S. (2006) Research on Telecom Business Model Based on Value Network. Beijing University of Posts and Telecommunications, Beijing.

[21] Grasl, O. (2009) Business Model Analysis-Method and Case Studies. University of St. Gallen, Switzerland.

[22] Hajiheydari, N. and Zarei, B. (2013) Developing and Manipulating Business Models Applying System Dynamics Approach. Journal of Modelling in Management, 8 , 155-170. https://doi.org/10.1108/JM2-11-2011-0058

[23] Li, Y.Y. (2014) Research on Internet of Things Business Model Based on Value Network. Shandong University, Jinan.

[24] Dai, M. and Chen, L.J. (2014) Research on CSO Business Model and Its System Dynamics Simulation. Soft Science, 28, 119-123.

[25] You, J.P. (2015) The Influence of Business Model of Chinese Real Estate Enterprises on Firm Growth Based on System Dynamics. Systems Engineering, 33, 105-113. 